\title{
Two-way interactions between music and language: Evidence from priming recognition of tune and lyrics in familiar songs
}

\author{
ISABELLE PERETZ \\ University of Montreal, Montreal, Quebec, Canada \\ MONIQUE RADEAU \\ Free University of Brussels, Brussels, Belgium \\ and \\ MARTIN ARGUIN \\ University of Montreal, Montreal, Quebec, Canada
}

\begin{abstract}
A priming technique was employed to study the relations between melody and lyrics in song memory. The procedure involved the auditory presentation of a prime and a target taken from the same song, or from unrelated but equally familiar songs. To promote access to memory representations of songs, we varied the format of primes and targets, which were either spoken or sung, using the syllable /la/. In each of the four experiments, a prime taken from the same song as the target facilitated target recognition, independently of the format in which it occurred. The facilitation effects were also found in conditions close to masked priming because prime recognizability was very low, as assessed in Experiment 1 by $d^{\prime}$ measures. Above all, backward priming effects were observed in Experiments 2, 3 , and 4, where song order was reversed in the prime-target sequence, suggesting that words and tones of songs are not connected by strict temporal contingencies. Rather, the results indicate that, in song memory, text and tune are related by tight connections that are bidirectional and automatically activated by relatively abstract information. Rhythmic similarity between linguistic stress pattern and musical meter might account for these priming effects.
\end{abstract}

Songs are a primary source of interest for scholars studying the relation between music and language. In songs, the text seems to merge so perfectly into the melody that music and language do not appear to be separate entities. This phenomenon has led some researchers to argue that lyrics and melody representations are not separate but integrated in memory for songs (Serafine, Crowder, \& Repp, 1984; Serafine, Davidson, Crowder, \& Repp, 1986). However, there is increasing evidence, especially from neuropsychology, that the music and language components of songs maintain autonomy in perception (e.g., Besson, Faïta,

The research was supported by a grant from the Medical Research Council of Canada and a grant from the Natural Science and Engineering Research Council of Canada to I.P. M.A. is chercheur-boursier of the Fonds de la Recherche en Santé du Québec. We acknowledge the assistance of Cédric Hanon, Patricia Jelenic, Julie Ayotte, Amélie Racette, Mylène Valiquette, and Evelyne Touchette in testing the participants, and the assistance of Bernard Bouchard, Sylvie Hébert, and Nathalie Gosselin in constructing and adjusting the materials. We would like to express our gratitude to the editor, Colin MacLeod, and Régine Kolinsky, Bruno Repp, Serge Larochelle, and three anonymous reviewers for taking the time to write helpful detailed comments on an earlier draft of this article. Correspondence should be addressed to I. Peretz, Department of Psychology, University of Montreal, C.P. 6128 Succursale Centre-Ville, Montreal, PQ, H3C 3J7 Canada (e-mail: isabelle.peretz@umontreal.ca).
Peretz, Bonnel, \& Requin, 1998), in memory (e.g., Peretz, 1996), and in singing (Hébert, Racette, Gagnon, \& Peretz, 2003). Therefore, it is important to understand how words are combined with notes to give rise to such an apparent fusion of the two song components. Answering this question is the long-term objective of the present study.

The immediate goal of the present set of experiments was to provide a method to study the nature of the connections between melody and lyrics in song memory. The prevailing paradigm in the field, involving the recognition of isolated novel songs (Crowder, Serafine, \& Repp, 1990; Morrongiello \& Roes, 1990; Samson \& Zatorre, 1991; Serafine et al., 1984; Serafine et al., 1986), is not the most appropriate tool for such explorations. The method consists of presenting short song fragments to participants with the instruction to recognize these immediately afterward among similar fragments. This is a very difficult task for the listener and a very demanding setting for the experimenter, who must perform ingenious and extensive manipulation of the song material. More importantly, the recognition memory paradigm is an off-line and laborious task that is quite remote from the normally smooth and effortless process of song recognition.

In contrast, the priming paradigm that is exploited here is an on-line task that has been frequently and successfully 
used to study the associations in memory that are automatically activated. Hence, the adaptation of a priming task to the study of the relations between lyrics and tune in song memory was deemed to be both timely and worthwhile. Before explaining how we used the priming technique here, we review what has been learned about song memory with the recognition memory paradigm.

\section{Recognition Memory of Novel Songs}

In the recognition memory task, participants study a list of 24 unfamiliar short folk songs that are presented only once auditorily. A recognition test follows immediately in which the participants are asked to indicate, for a series of similar fragments, whether they have heard the song, the text, or the melody previously. The foils are either completely new songs (new melody and new lyrics) or a recombination in which either a new melody is combined with studied lyrics or new lyrics are combined with a previously studied melody. The lyrics and melody of different study songs may also be recombined to form new songs, which are referred to as "mismatch songs." From this special arrangement of test songs, one can study the nature of the associations between text and melody in song memory.

Listeners systematically show evidence of retention of the original (studied) association between melody and text, even after a single hearing. They always recognize the text and tune in the original pairing better than in the new, mismatched, one (Crowder et al., 1990; Samson \& Zatorre, 1991; Serafine et al., 1984, Serafine et al., 1986). The learned association does not seem to depend on the semantic content of the lyrics. Recognition of original songs remains higher than recognition of mismatch songs when melodies are sung with nonsense syllables (Crowder et al., 1990; Serafine et al., 1986). Retrieval of the associated text also appears mandatory. Listeners fail to ignore the text even though they are required to recognize the melody component only (Crowder et al., 1990; Serafine et al., 1986). Finally, the phonological structure of the syllables seems to play a role in this mandatory association. Participants recognize a melody better when repeated with nonsense words that are phonetically similar to the nonsense syllables with which that melody was originally presented than when it is heard with syllables that are phonetically dissimilar from the original (Crowder et al., 1990). Thus, the association between text and tune in song memory appears robust, involuntary, and related to perceptual rather than semantic similarities.

The nature of these perceptual connections between text and melody are probably not acoustical. Recognition of the melody of a song remains higher in the presence of the text with which it has been heard originally when melody and text are presented in separate streams. Crowder et al. (1990, Experiment 3) presented spoken texts accompanied by hummed melodies. In these "divided" songs, lyrics and melodies were connected (in time) but were acoustically distinct. Participants again recognized the melody better when it was paired with the matched studied text (true old pair) than when it was paired with another old text (mis- matched pair). The presence of superior recognition for the old pairing over the mismatched one shows that the learned association between text and melody can arise from simple time contingencies.

An association by time contingency reflects the fact that two events that are experienced in close temporal proximity become connected in memory so that each acts as a recognition cue for the other. Although this explanation is sufficient to account for the association between text and melody in a single line from a song, it may have to be modified to account for the retention of a whole song verse or chorus.

At the level of the whole song, time contingencies between lyrics and melody are more complex and asymmetrical (Peretz, 1993). Songs are usually built around a few melodic lines, each carrying different lyrics. That is, a single melody typically carries many different lyrics, whereas a single text line is rarely set to different melodic lines. The memory consequences of this particularorganization are that a melody will be a poor index for a specific text, whereas song lyrics should be quite diagnostic of a specific tune. Another memory consequence of this assumed asymmetry of lyrics and melodies in songs is that the frequent repetition of the melody (with different word settings) should increase its memorability relative to text.

Despite their simplicity, these hypotheses regarding the strength and directionality of the connections (or contingencies) between melody and text have never been tested. They served as the departure point for the use of a priming paradigm in the present study.

\section{A Priming Paradigm for Songs}

Priming is a well-known phenomenon that has been effectively employed to reveal the organization of information stored in memory. Priming is generally defined as a modification in performance due to the prior processing of an item that is related to the target. In seminal experiments (Meyer \& Schvaneveldt, 1971), participants were presented with two items and had to make a lexical decision about the second item, the target (e.g., "Is DOCTOR a word?"). When the target was closely related to the preceding item (e.g., NURSE), response latency to the target was quicker than when an unrelated item (e.g., WALL) preceded the target. NURSE, as opposed to the unrelated WALL, is said to prime DOCTOR. Such priming was assumed to reflect the organization of semantic memory. As the abundant literature suggests (e.g., Neely, 1991), priming may reveal the dynamics of many different memory systems.

The consensual account of the priming effect begins with the assumption that the prime makes contact with a stored representation in memory, and that this representation is left in a state of activation (e.g., Collins \& Loftus, 1975). To account for priming, it is further assumed that activation spreads to the representations of related items. This partial level of activation confers an advantage on the related target, which will be processed more efficiently than if it had not been primed. The usefulness of these functional principles for understanding the structure and organization 
of stored information has been demonstrated in many domains. In addition to semantic memory, mental lexica, which contain distinct stores of phonological and orthographic representations of words, have been similarly and successfully explored with priming techniques (see Zwitserlood, 1996, for a review). The way words from different languages are related in the memory of bilinguals (Tzelgov \& Eben-Ezra, 1992) and the way familiar faces are represented and linked to proper names (e.g., Young, Hellawell, $\&$ De Haan, 1988) have also been revealed by priming experiments.

Similarly, the way lyrics and song melodies are associated in memory might be uncovered by priming procedures. More specifically, the amount and directionality of priming from melody to text and vice versa should inform us concerning the nature of the associations in song memory. The presentation of lyrics is expected to activate their representation in memory, which in turn is expected to activate the corresponding melody representation. If activation flows better or more quickly from lyrics to melodies than from melodies to lyrics, as predicted by the way familiar songs are constructed, then lyrics should facilitate melody recognition more effectively than melody would for lyrics recognition. In other words, the amount of priming should depend on the direction in which activation must spread between melody and text representations.

Since the objective was to study the connections between melody and text in memory, not in perception, presentation of song components was made as acoustically dissimilar as possible. Thus, lyrics were spoken, and melodies were sung using the syllable / la/. On each trial, a participant was thus presented with a few sung notes (or spoken text) followed by a few spoken words (or sung melody). The task was to perform a go/no-go familiarity decision about the second item, either spoken or sung, by pressing a button as quickly as possible whenever the text (the melody) was judged to be coming from a well-known song. Half of the targets came from such familiar songs and half came from unfamiliar ones. The latter items were taken from songs unknown to the population from which our participants were drawn.

To elicit priming effects in the recognition of the familiar targets, primes were taken either from the same song or from a different but equally familiar song. For example, the lyrics "My Bonnie lies over the ocean" were expected to prime the sung segment "Bring back," which comes from the same song, and not to prime the sung segment "to you," which is taken from another familiar song ("Happy Birthday"). These straightforward predictions derive from the application of the priming principles previously summarized. That is, two excerpts of the same song are likely to benefit more from spread of activation than are two excerpts coming from different, unrelated, songs. Finding such differences in priming between related and unrelated pairs is not informative with regard to the direction of the associations. However, it is necessary to demonstrate such priming effects to prove that performance reflects contact with information contained in song memory. The key effects with regard to the direction of the relation lie in the relative ease of recognition of lyrics (melody) when primed by melody (lyrics).

It turned out that recognizability of text and melody was difficult to match. Even though musical and speech components are as close as possible in terms of structure and familiarity, because they are taken from the same segment of a preexisting song, lyrics and melodies still differ in a number of aspects that may interfere with the effects of the memory organization under study. Thus, each of the four experiments in the present study was designed to improve the comparability between song components.

We started by presenting the song material in the same sequential order as it appears in the real song. That is, primes were beginnings and targets were continuations in Experiment 1. Melodic continuations proved to be hard to recognize in isolation. Thus, in Experiments 2-4, the song order was reversed: Beginnings of songs were presented as targets and continuations as primes. Such a procedure is akin to backward priming, as used in semantic priming studies (e.g., Kahan, Neely, \& Forsythe, 1999; Koriat, 1981), where direction of the verbal association is not respected. For example, in free association, BABY is frequently given after STORK whereas STORK is almost never provided after BABY. Yet, the word STORK primes the word BABY. This finding increased the likelihood that we would observe similar results with song parts by backward association. This expectation was fulfilled.

However, the priming pattern was different depending on whether melody or lyrics served as target. To assess whether the different priming patterns could be due to differences in stimulus duration, in Experiment 3, melodies were matched to lyrics in duration by time compression. Because lyrics remained easier to recognize than melodies, lyrics recognizability was matched to the melody recognition level by embedding lyrics in noise in Experiment 4.

\section{EXPERIMENT 1 Targets as Song Continuations}

In this initial experiment, primes and targets were presented in the order in which they occur in the real song. That is, primes corresponded to beginnings of songs and targets to continuations, as illustrated in Table 1. An English example would consist of "My Bonnie lies over the ocean" as prime, and "bring back" as target. In such a related pair, the recognition of targets should be very quick. However, the same target ("bring back") should be difficult to recognize when preceded by an unrelated song part, such as "Happy birthday." Thus, target recognition was expected to be quick and accurate in related trials, and slow and inaccurate in unrelated ones. Conditions that yield high error rates are not well suited to studying response times. Therefore, accuracy measures, especially sensitivity measures that are derived from signal detection analyses, were used instead.

The main objective of this initial experiment was to assess whether priming effects could be obtained on both 
Table 1

Examples of Spoken Primes and Targets, and Their English Analogs, as Used in Experiment 1

\begin{tabular}{|c|c|}
\hline Prime & Target \\
\hline \multicolumn{2}{|c|}{ Related } \\
\hline $\begin{array}{l}\text { Frère Jacques } \\
\text { My Bonnie lies } \\
\text { over the ocean } \\
\text { Au clair de la lune } \\
\text { Happy birthday }\end{array}$ & $\begin{array}{l}\text { dormez-vous } \\
\text { bring back } \\
\text { mon ami Pierrot } \\
\text { to you }\end{array}$ \\
\hline \multicolumn{2}{|c|}{ Unrelated } \\
\hline $\begin{array}{l}\text { Frère Jacques } \\
\text { Happy birthday } \\
\text { Au clair de la lune } \\
\text { My Bonnie lies } \\
\text { over the ocean }\end{array}$ & $\begin{array}{l}\text { mon ami Pierrot } \\
\text { bring back } \\
\text { dormez-vous }\end{array}$ \\
\hline
\end{tabular}

melody and text recognition of familiar songs. Therefore, all possible pairings between melody and text were examined. In the lyrics-lyrics condition, both primes and targets were spoken. In the melody-melody condition, both primes and targets were sung. These two conditions, in which there is no change of song component between prime and target, served as baseline conditions because they were expected to elicit highly robust priming effects. Examination of the direction of association between text and melody is conditional on obtaining these baseline priming effects. Indeed, before testing the direction of the associative links, we first need to show that both the sung and spoken presentations of different segments of the same song facilitate access to their respective memory representations. This was the major goal of this experiment.

\section{Method}

Participants. Sixty-four university students (mean age: 24 years) were assigned randomly, but in equal numbers, to one of the four experimental conditions. They were all first-year undergraduate students, which ensured that participants had not yet heard about priming experiments in class. The majority had no musical training. Twenty-two participants reported having had some nonprofessional training in music, varying from 2 to 10 years of practice with a musical instrument. All participants were native speakers of French, and had been brought up in Quebec since at least the age of 2, which ensured homogeneity of song knowledge. They were paid for their participation.

Materials. Stimuli were taken from folk songs. The choice of stimuli was very limited for several reasons. First, primes and targets had to differ acoustically, phonologically, and musically. Second, the familiar segments needed to be recognizable with a minimal number of tones or syllables, to keep stimuli as short as possible. This duration criterion was used to minimize variations in decision times and to encourage rapidity. Several pilot studies were undertaken to arrive at the set of stimuli used in the present experiment (the written notation of the stimuli can be downloaded from www.fas.umontreal.ca/ psy/iperetz.html).

The set of stimuli comprised 48 beginnings of familiar songs, which served as primes; 24 excerpts coming from later portions of these same songs, to serve as familiar targets; and 24 unfamiliar targets taken from the same repertoire of folk songs (Berthier, 1979). These were considered unfamiliar because they are no longer sung or played. However, all targets sounded somewhat unfamiliar as attested by the ratings provided by 10 pilot participants. The 24 targets taken from highly familiar songs and the 24 targets taken from the unknown songs received mean ratings of 4.1 and 2.9 , respectively, on a 10-point scale $(10=$ highly familiar $; 1=$ unfamiliar $)$. Although the difference reached significance $[t(46)=3.08, p<.001]$, the ratings indicate how difficult the familiarity decision task is for targets from later portions of songs.

In 12 prime-target pairs, the relation between prime and target was preserved: The target was generally a direct continuation of the prime. In the other 12 pairs involving a familiar target, the prime and target were unrelated. This was done by interchanging primes and targets, as illustrated in Table 1. Thus, there were 24 familiar targets, 12 of which were preceded by related primes, and 12 by unrelated primes. Two lists were generated so that one particular target appeared with its related prime in one list and with its unrelated prime in the other list. Thus, all targets were presented in both priming contexts, but only once in a given list. In addition to the 24 trials involving a familiar target, 24 trials composed of a familiar prime and an unfamiliar target were presented. To eliminate any predictive value of prime type for the target stimulus, the prime was always familiar. The 48 prime-target pairs were mixed in two different random orders for each list.

Each of the four possible lists was recorded in four versions. In the melodic version, both prime and target were sung using the syllable /la /. In the spoken version, both prime and target were lyrics spoken with a natural intonation. That is, special care was taken to pronounce the words with a normal French timing intonation. The sung and spoken versions were produced by the same female singer. From these two "same-domain" versions, two "cross-domain" versions were generated. This was achieved by interchanging the melody and lyrics primes. For example, the melody prime in the melody-melody version was replaced by its spoken version to create the lyrics prime-melody target pair in the cross-domain condition. Song excerpts and presentation order were the same across versions.

To summarize, the stimulus materials consisted of four versions corresponding to four experimental conditions. Each version was arranged into two lists with two possible orders, amounting to four different sets per version, each involving 48 experimental trials.

Apparatus and Procedure. The stimuli were digitized at a sampling rate of $44.1 \mathrm{kHz}$ using a 16-bit analog-to-digital converter, and equalized for intensity via the Soundtools program from Digi Design on a Macintosh II FX computer. The stimuli were stored as files on a computer disk for real-time presentation to participants via a digital interface amplifier and Sennheiser headphones. Stimulus presentation and response recordings were achieved via the Experimenter Package for the Apple Macintosh Computer (Wathanasin, Birkett, Russell, \& Altmann, 1991).

Each participant was presented with only one list comprising 48 experimental trials preceded by 22 practice trials. The practice stimuli were taken from songs that were not used in experimental trials and only comprised unrelated trials. The practice trials involved the same priming conditions as the experimental trials, the four conditions being tested across participants. The fact that all participants were presented with the same targets (but not the same priming context) means that any response difference cannot be ascribed to stimulus differences.

All trials began with a warning beep in the ear receiving the prime, followed immediately and binaurally by the target. This difference in ear of presentation between prime and target allowed the listener to clearly distinguish the target, which was perceived in the middle of the head, from the prime, which was perceived as coming from the ear receiving the beep. The interstimulus interval (ISI) between prime and target was set to $0 \mathrm{msec}$ so as to leave no time for strategic consideration of the prime. Finally, the stimulus onset asynchrony (SOA) between prime onsets was maintained at a constant duration of 6 sec to reduce time uncertainty.

Participants were instructed to ignore the monaural prime and to make a familiarity decision to the binaural target only. A go/no-go 
Table 2

Experiment 1: Mean $d^{\prime}$ and Standard Error for Familiar Targets as a Function of Prime-Target Relation and Condition Target

\begin{tabular}{|c|c|c|c|c|c|c|c|c|}
\hline \multirow[b]{3}{*}{ Prime } & \multicolumn{4}{|c|}{ Melody } & \multicolumn{4}{|c|}{ Lyrics } \\
\hline & \multicolumn{2}{|c|}{ Related } & \multicolumn{2}{|c|}{ Unrelated } & \multicolumn{2}{|c|}{ Related } & \multicolumn{2}{|c|}{ Unrelated } \\
\hline & $M$ & $S E$ & $M$ & $S E$ & $M$ & $S E$ & $M$ & $\overline{S E}$ \\
\hline Same-domain & 1.15 & 0.15 & $0.07 *$ & 0.10 & 3.21 & 0.20 & 1.67 & 0.18 \\
\hline Cross-domain & 1.36 & 0.18 & $0.20 *$ & 0.16 & 2.32 & 0.19 & 1.11 & 0.15 \\
\hline
\end{tabular}

*Not significantly above chance by two-tailed $t$ tests.

procedure was used to promote speed in responding. Thus, participants were requested to press a button connected to a computer as quickly as possible when the binaural excerpt was from a familiar song and to withhold responding when it was not. Both speed and accuracy were emphasized and no feedback was provided. The session lasted $20 \mathrm{~min}$.

\section{Results and Discussion}

Discriminability $d^{\prime}$ measures were computed for each participant. Keypresses given to targets coming from familiar songs were considered as hits, and responses given to unfamiliar targets as false alarms. Response times could not be meaningfully analyzed because participants failed to recognize many targets when these were preceded by unrelated primes. In fact, performance was at chance in the two conditions involving sung targets preceded by unrelated primes (Table 2), indicating that the melodic parts of songs are hard to recognize. In general, melodic targets appeared to be more difficult to recognize than their spoken counterparts.

The $d^{\prime}$ measures were submitted to an analysis of variance (ANOVA) with condition (same- vs. cross-domain) and target type (sung or spoken) as between-subjectsfactors and relatedness (related vs. unrelated) as a within-subjects factor. The analysis revealed two main effects: target type and relatedness. The target type effect reflects the fact that lyrics are easier to recognize than melodies $[F(1,60)=$ $\left.92.81, M S_{\mathrm{e}}=0.65, p<.001\right]$. This difference in recognizability did not affect the magnitude of priming effects. The priming effects were clearly present in each condition, as supported by a main effect of relatedness $[F(1,60)=219.36$, $\left.M S_{\mathrm{e}}=0.22, p<.001\right]$. There was no relatedness $\times$ condition interaction $(F<1)$, no relatedness $\times$ target interaction $\left[F(1,60)=2.40, M S_{\mathrm{e}}=0.22\right]$, and no relatedness $\times$ target $\times$ condition interaction $\left[F(1,60)=1.54, M S_{\mathrm{e}}=0.22\right]$.

Thus, beginnings of songs facilitate the recognition of later portions of the same song, whether the segments are spoken or sung. The presence of these priming effects shows that the technique is sound for exploring the organization of text and melody in memory for songs. Furthermore, the fact that the effects of a sung prime on the recognition of lyrics did not differ from the effects of lyrics on the recognition of melodies runs against our hypothesis that the strength of the links between lyrics and melody is asymmetrical. However, the spoken prime may have had a dual function here. The starting lyrics of a song often serve both as the text to be sung first and as the name of the song. This was the case for 21 of the 24 spoken primes used here. Therefore, the spoken, as opposed to the sung, primes might have boosted expectations for the song continuation on account of their double status in memory. Consideration of the prime as the song name will be avoided in the following experiments, in which the prime-target order is reversed.

\section{EXPERIMENT 2 Prime and Target in Reverse Order}

In this experiment, the design and stimuli were the same as in Experiment 1 except that song beginnings were presented as targets for recognition instead of as primes. For example, participants were presented here with "bring back" in one ear, immediately followed by "My Bonnielies over the ocean" in both ears; their task was to decide whether "My Bonnie lies over the ocean" comes from a familiar song. The response should be fairly rapid and the prime should no longer be confounded with the song title. A possible cost for violating song order is that it may decrease priming considerably. Thus, the primary goal of Experiment 2 was to verify that priming effects are obtained when song order is not respected. Because it soon became apparent that large priming effects were elicited in such conditions, the two key conditions that involve a change from text to melody and vice versa were also included. Therefore, the design and predictions for Experiment 2 were identical to those for Experiment 1.

\section{Method}

Participants. Ninety-six first-year university students (mean age: 22 years) who had not participated in Experiment 1 were selected and assigned to the four conditions according to the same criteria. Half were nonmusicians (they had never learned to play an instrument), and half had practiced an instrument for 3-12 years.

Materials, Design, and Procedure. The stimuli were taken from the same pool of 48 familiar songs as in Experiment 1. The only procedural difference from Experiment 1 was that beginnings of songs were used as targets instead of as primes.

In line with prior use of the priming technique, the response times were considered as the major dependent variable. In that context, it should be mentioned that the sung stimuli have a longer duration than the spoken ones. Despite several attempts to speed up the singing rendition of the melodies and to slow down the articulation of the lyrics, the sung version remained longer than the spoken version by about $35 \%$. The average durations of sung primes and targets were 2,202 and 2,496 msec, respectively. The average durations for the spoken primes and targets were 1,495 and $1,626 \mathrm{msec}$, respectively.

\section{Results and Discussion}

Responses were scored as correct if the key was pressed within a time window lasting from $300 \mathrm{msec}$ after target onset to $500 \mathrm{msec}$ after target offset. The rate of rejection was less than $1 \%$ of the data. Misses (no keypress) and false alarms (keypress when inappropriate) were scored separately. Only response latencies for correct responses (hits) were analyzed. The mean response latencies for the correct recognition of targets are presented in Table 3 along with the percentages of misses and their respective standard errors. False alarms averaged $15 \%$ and did not vary with 
Table 3

Experiment 2: Mean Response Times (RTs, in Milliseconds),

Percentage of Misses (PM), and Standard Error for Familiar Targets as a Function of Prime-Target Relation and Condition

\begin{tabular}{|c|c|c|c|c|c|c|c|c|c|c|c|c|c|c|c|c|}
\hline \multirow[b]{4}{*}{ Prime } & \multicolumn{16}{|c|}{ Target } \\
\hline & \multicolumn{8}{|c|}{ Melody } & \multicolumn{8}{|c|}{ Lyrics } \\
\hline & \multicolumn{4}{|c|}{ Related } & \multicolumn{4}{|c|}{ Unrelated } & \multicolumn{4}{|c|}{ Related } & \multicolumn{4}{|c|}{ Unrelated } \\
\hline & RT & $S E$ & PM & $S E$ & RT & $S E$ & PM & $S E$ & RT & $S E$ & PM & $S E$ & RT & $S E$ & PM & $S E$ \\
\hline Same-domain & 1,652 & 59 & 9 & 2 & 1,910 & 66 & 15 & 2 & 868 & 28 & 5 & 1 & 1,070 & 29 & 8 & $\overline{1}$ \\
\hline Cross-domain & 1,719 & 42 & 8 & 2 & 1,852 & 56 & 14 & 2 & 942 & 25 & 8 & 1 & 1,028 & 25 & 8 & 2 \\
\hline
\end{tabular}

condition or target type. Analyses of the miss rates are presented following the analyses of response times.

As can be seen in Table 3, reversing the order in which prime and target naturally occur in songs did not abolish priming effects. Beginnings of songs are more accurately and more quickly recognized when they follow the presentation of an excerpt from the same song (related trials) than when they follow an excerpt from a different song (unrelated trials). As anticipated, participants recognized the text of songs much more quickly than the corresponding melody. Because this difference could be due to the difference in duration of the stimuli rather than to some interesting difference between sung and spoken targets, the latencies obtained with sung and spoken targets were subjected to separate ANOVAs.

Analyses were performed both with subjects as the random factor $\left(F_{1}\right)$ and with items as the random factor $\left(F_{2}\right)$. The data were analyzed according to two factors: condition (same- vs. cross-domain) and relatedness (related vs. unrelated). In the subjects analysis, condition was treated as a between-subjects factor and relatedness as a within-subjects factor. In the items analysis, both factors were treated as within-songs variables.

For sung targets, the priming effects, reflected by shorter latencies to targets preceded by primes coming from the same song, were very robust both by subjects $\left[F_{1}(1,23)=\right.$ $\left.13.80, M S_{\mathrm{e}}=66,171, p<.001\right]$ and by items $\left[F_{2}(1,23)=\right.$ $\left.23.04, M S_{\mathrm{e}}=29,046, p<.001\right]$. The effect seems to be as large after a sung as after a spoken prime. The interaction between condition and relatedness was absent for subjects $\left[F_{1}(1,46)=1.40, M S_{\mathrm{e}}=66,171\right.$, n.s. $]$ but was close to significance for songs $\left[F_{2}(1,23)=3.77, M S_{\mathrm{e}}=27,862, p<.10\right]$.

In contrast, for spoken targets, the interaction between condition and relatedness did reach significance in both types of analyses $\left[F_{1}(1,46)=10.02, M S_{\mathrm{e}}=8.043, p<\right.$ .003 , and $\left.F_{2}(1,23)=7.13, M S_{\mathrm{e}}=11,940, p<.02\right]$, reflecting the fact that the priming effect was largest when both prime and target were spoken. Significant priming effects were, however, obtained in each condition (the $t$ values were 3.11 by subjects and $2.17, p<.05$ by items in the cross-domain condition, where spoken targets were primed by a sung melody).

Miss rates were low, confirming the intuition that the beginnings of songs are easy to recognize. The miss rates were subjected to two overall ANOVAs, one with subjects as the random variable and the other with items. In both analyses, condition (within- vs. cross- domain), target type (melody vs. lyrics), and relatedness were the factors of interest. Only two main effects were obtained. The effect for relatedness $\left[F_{1}(1,92)=9.41, M S_{\mathrm{e}}=0.0074\right.$, and $F_{2}(1,46)=$ $\left.9.58, M S_{\mathrm{e}}=0.0073, p<.003\right]$ shows that targets are generally easier to recognize when preceded by an excerpt coming from the same song than otherwise. The other main effect to reach significance was target type, but only in the analysis performed by subjects $\left[F_{1}(1,92)=12.25, M S_{\mathrm{e}}=\right.$ $0.0068, p<.001 ;$ since $F_{2}<1$ ], indicating an advantage of lyrics over melodies in recognizability. No interaction reached significance.

As in Experiment 1, reliable priming effects were obtained in song part recognition even though primes and targets were not presented in the same sequential order as in the original song but in a backward direction. Response times were much quicker when the song beginning was preceded by a segment coming from the same song than when it was preceded by a segment from a different song. However, the amount of priming taken to reflect the strength of the connections between melody and text seems compatible with the way familiar songs are constructed. Text fragments facilitated the recognition of melodies as much as the melodic fragments did. In contrast, melodic fragments did not facilitate recognition of lyrics as much as another text fragment did. The evidence is indirect, though, because the data obtained in the two cross-domain conditions could not be compared.

The difference in response latencies for the text and the melody targets is considerable. It takes about half as long to recognize the lyrics of a familiar song than to recognize its music. This difference in response times might be due to the difference in stimulus duration. The lyrics had a much shorter duration than the melodies, reflecting the fact that singing is much slower than speaking (see Kilgour, Jakobson, \& Cuddy, 2000, for converging evidence). The problem with this difference in stimulus duration is that it might influence priming. Because the information is provided more quickly in the spoken stimulus than in the sung one, the lyrics are likely to make contact with the memory representation earlier than the melody. Activation is generally construed as having a short time course. Hence, by making an earlier contact, the lyrics may spread more activation than the melody. This advantage of words over notes would not be related to the strength or the directionality of the connections linking lyrics and melodies. Instead, it 
would reflect a difference in stimulus duration. The goal of Experiment 3 was to abolish this difference between melody and text by matching stimulus durations.

\section{EXPERIMENT 3 Time Compression of Melodies}

In Experiment 3, we sought to match the duration of the lyrics and of the melody part of the same song so as to be able to compare recognition latencies. To this aim, the sung versions were time compressed; the result sounded more natural than the slowing down of the spoken stimuli. We also increased the number of observations per participant. Participants were presented with the same targets twice, once in the context of a related prime and once in the context of an unrelated prime. Otherwise, the task and experimental conditions were identical to those of Experiment 2.

\section{Method}

Participants. Ninety-six first-year-uni versity students (mean age: 23 years) who had not participated in the previous experiments were assigned randomly to the four conditions of the experiment. There were twice as many participants in the two conditions involving sung targets ( 32 in each condition) as in the two conditions involving spoken targets (16 in each condition) because compressed melodies were much harder to recognize than anticipated. Hence, the size of the sample was increased to compensate for the decreased number of observations per participant relative to the two conditions involving spoken targets.

Materials and Procedure. Each sung prime and target was compressed so as to match the duration of its corresponding spoken version. Compression rates varied between $3 \%$ and $60 \%$ (with a mean of $33 \%$ for familiar targets) and were performed using the Soundtool program from Digi Design. These compressed files replaced the uncompressed melodies used in Experiment 2. Thus, the pairing of primes and targets and the order of presentation were identical in the two experiments. The only further change was that participants were presented with both lists of 48 trials instead of a single one. Care was taken to present the two lists that had a different randomized order of presentation. The order of presentation of the lists was counterbalanced across participants in each condition.

Each participant performed the same task on the two lists, amounting to 96 trials preceded by 22 practice trials. It should be recalled that the two lists differed only in the arrangement of prime-target relation. That is, any given familiar target was presented twice to each participant, once preceded by a related prime and once by an unrelated prime. The potential effect of target repetition on performance will be assessed statistically.

The task requirements, the apparatus, and the scoring procedure were the same as those used in Experiment 2.

\section{Results and Discussion}

The mean correct latencies are presented along with the miss rates and standard errors in Table 4 . The miss rates include the responses that were rejected for exceeding stimulus duration by more than $500 \mathrm{msec}$, following the scoring procedure adopted in Experiment 2. The rate of outliers in response times was much higher for the compressed melodies than for spoken targets, with $10 \%$ versus $2 \%$ of the data, respectively. Because the core results are not affected by this stringent criterion, as attested to by the output of the analyses performed on the median response times uncorrected for outliers, the scoring procedure was maintained. Thus, the results described here were obtained with mean correct response times for responses given before the end of the 500-msec poststimulus window.

A first analysis was performed to assess the effect of target repetition on performance. This ANOVA considered target presentation (initial vs. repeated) and prime-target relatedness (related vs. unrelated) as within-subjects factors, and condition (same vs. across) and target type (melody vs. lyrics) as between-subjects factors. All factors were considered within items in the ANOVA computed for songs. Both ANOVAs yielded a main effect of repetition $\left[F_{1}(1,92)=60.72, M S_{\mathrm{e}}=10,722\right.$, and $F_{2}(1,23)=46.97$, $M S_{\mathrm{e}}=14,527$, both $\left.p \mathrm{~s}<.001\right]$, showing that response times were systematically shorter when the target was heard the second time. Because this repetition effect did not interact with any of the other factors and showed similar effects on the error patterns, target repetition was not considered in the analyses.

As can be seen in Table 4, time compression did not succeed in canceling latency differences between sung and spoken versions of the targets; spoken targets remained more quickly recognized than sung targets, at $931 \mathrm{vs.} 1,416 \mathrm{msec}$, respectively $\left[F_{1}(1,92)=150.85, M S_{\mathrm{e}}=66,354, p<.001\right.$; $\left.F_{2}(1,23)=85.43, M S_{\mathrm{e}}=122,929, p<.001\right]$. As in Experiment 2 , the magnitude of the priming effect depended on the domain in which the prime and the target were presented. Priming appeared to be reduced by a change in domains when the targets were spoken, whereas there was no evidence for such a reduction when the target was sung. This asymmetric pattern is supported by a triple interaction between condition, relatedness, and target domain $\left[F_{1}(1,92)=\right.$ $17.42, M S_{\mathrm{e}}=3,529, p<.001$, and $F_{2}(1,23)=9.12, M S_{\mathrm{e}}=$ $6,302, p<.01]$.

Table 4

Experiment 3: Mean Response Times (RTs, in Milliseconds), Percentage of Misses (PM), and Standard Error for Familiar Targets Matched in Duration as a Function of Prime-Target Relation and Condition

Target

\begin{tabular}{|c|c|c|c|c|c|c|c|c|c|c|c|c|c|c|c|c|}
\hline \multirow[b]{4}{*}{ Prime } & \multicolumn{16}{|c|}{ Target } \\
\hline & \multicolumn{8}{|c|}{ Melody } & \multicolumn{8}{|c|}{ Lyrics } \\
\hline & \multicolumn{4}{|c|}{ Related } & \multicolumn{4}{|c|}{ Unrelated } & \multicolumn{4}{|c|}{ Related } & \multicolumn{4}{|c|}{ Unrelated } \\
\hline & RT & $S E$ & PM & $S E$ & RT & $S E$ & $\mathrm{PM}$ & $S E$ & RT & $S E$ & PM & $S E$ & RT & $S E$ & $\mathrm{PM}$ & $S E$ \\
\hline Same-domain & 1,374 & 38 & 19 & 2 & 1,443 & 41 & 23 & 3 & 811 & 31 & 5 & 1 & 1,008 & 23 & 7 & $\overline{1}$ \\
\hline Cross-domain & 1,371 & 33 & 16 & 1 & 1,475 & 34 & 24 & 2 & 913 & 35 & 3 & 1 & 993 & 39 & 5 & 1 \\
\hline
\end{tabular}


Further analyses were performed to assess the effect of prime condition on each type of target. When the target was sung, it was more quickly recognized when preceded by a related than by an unrelated prime $\left[F_{1}(1,62)=59.59\right.$, $M S_{\mathrm{e}}=3,965, p<.001$, and $F_{2}(1,23)=34.50, M S_{\mathrm{e}}=4,574$, $p<.001]$. Priming was as robust when the prime was sung as when it was spoken. The interaction between condition and relatedness did not reach significance $\left[F_{1}(1,62)=2.54\right.$, $M S_{\mathrm{e}}=3,965, p>.10$, and $\left.F_{2}<1\right]$.

In contrast, as in Experiment 2, the pattern was different when the target was spoken. The priming effect was reduced after a sung prime, although it remained statistically reliable $[t(15)=4.99$ by subjects and $t(23)=5.82$ by items, both $p \mathrm{~s}<.001]$. The difference between the two conditions is supported by a significant interaction between prime-target relatedness and condition $\left[F_{1}(1,30)=20.59, M S_{\mathrm{e}}=2,627\right.$, and $F_{2}(1,23)=15.02, M S_{\mathrm{e}}=5,064$, both $\left.p \mathrm{~s}<.001\right]$.

As can be seen in Table 4, priming effects were more apparent on error rates when the target was sung than when it was spoken. This pattern was supported by an interaction between target type and prime-target relatedness $\left[F_{1}(1,92)=6.24, M S_{\mathrm{e}}=0.0029, p<.02 ; F_{2}(1,23)=7.32\right.$, $\left.M S_{\mathrm{e}}=0.0028, p<.02\right]$. This difference is probably due to the fact that spoken targets were almost perfectly recognized, with $95 \%$ correct responses on average, whereas participants were only $80 \%$ correct on sung targets. Melodic targets were clearly more difficult to recognize than spoken targets $\left[F_{1}(1,92)=57.34, M S_{\mathrm{e}}=0.168, p<.001\right.$, and $\left.F_{2}(1,23)=9.08, M S_{\mathrm{e}}=0.119, p<.01\right]$.

Matching the duration of lyrics and melodies thus did not have an impact on response latencies. Lyrics remained more quickly (and more accurately) recognized than melodies. Above all, lyrics recognition remained sensitive to the domain in which the prime was presented, whereas melody recognition did not. The results are once again more compatible with the view that lyrics are more tightly coupled to melodies than melodies are to lyrics. The fact that the same pattern of results was obtained in Experiment 2 suggests that the effects are not due to a difference in stimulus duration between melodies and lyrics.

However, as in the two prior experiments, the observation of a recognition advantage for text over melody is problematic. In particular, the systematic superiority of words over notes makes the comparison of priming effects between text and melody difficult to interpret. Any difference can be attributed, at least in part, to the fact that lyrics may prime song recognition by accessing the stored representation earlier than the melody. The goal of Experiment 4 was to eliminate any lyrics advantage by decreasing text intelligibility.

\section{EXPERIMENT 4 Noise Addition to Lyrics}

To eliminate the lyrics advantage, lyrics were embedded in noise. To keep duration comparable between melody and lyrics, melodies were again presented in the time- compressed format. The task and design were identical to those used in Experiments 2 and 3.

\section{Method}

Participants. Ninety-six students (mean age: 24 years) who had not participated in the previous experiments and who were selected according to the same criteria were tested, with 24 participating in each condition. About half of them had some musical experience.

Materials. The materials were identical to those used in Experiment 3 except for the addition of noise to all spoken stimuli. Lyrics were embedded in white noise with a variable ratio. The noise-tosound ratio was adjusted for each target, by way of the Soundtool program of Digi Design, to obtain a mean accuracy level of recognition performance comparable to the compressed melodies, namely $25 \%$ errors. To achieve this, several pilot studies were run and the signal-to-noise ratio was adjusted for each spoken target with levels of $10 \%, 20 \%$, or $30 \%$. The percentage of signal-to-noise ratio means that the loudness level of lyrics corresponded to this proportion, relative to the noise that was set to a constant loudness value of $100 \%$. All primes were presented at a ratio level of $20 \%$. To obtain an estimate of their residual recognizability, 10 control participants were asked to judge whether each prime embedded in noise sounded familiar (yes, familiar; no, unfamiliar; don't know). Only four of the 24 masked lyrics that served as primes for the familiar targets were judged to be familiar by the majority of the participants.

\section{Results and Discussion}

At the outset, it is worth mentioning that the lyrics were indeed as difficult to recognize as melodies in the present experiment. Participants were, on average, $74 \%$ correct on lyrics and $76 \%$ on melodies. The difference was not significant $[t(92)=1.00$ by subjects and $t(23)=0.41$ by items, both n.s.]. Thus, we succeeded in equating the recognizability of spoken lyrics and sung melodies as far as accuracy of the response is concerned, because lyrics were still identified more quickly than melodies, at 1,383 and $1,602 \mathrm{msec}$, respectively $[t(92)=4.21$ and $t(23)=5.72$, both $p$ s $<.001]$.

Nevertheless, because the material was adjusted to be comparable both in terms of duration (by time compression of melodies) and recognizability (by adding noise to lyrics), all conditions were considered in an overall ANOVA. A summary of the results is presented in Table 5. The same scoring procedure as the one previously used was adopted. Therefore, the ANOVA was performed on the mean latencies of correct responses obtained by subjects and by items, with condition (same- vs. across-domain) and target type (melody vs. lyrics) as the between-subjects factors, and prime relatedness (related vs. unrelated) as the withinsubjects factor. All factors were considered within items.

The remarkable aspect of the results is that the analyses did not reveal any difference in priming effects between conditions. There was no interaction between condition, targets, and relatedness factors ( $F_{1}$ and $F_{2}<1$ by subjects and by items, respectively), nor any interaction between any of these factors (all $F \mathrm{~s}<1$ ). There was, however, a highly robust priming main effect, with targets preceded by related primes being recognized more quickly than when preceded by unrelated primes $\left[F_{1}(1,92)=36.05, M S_{\mathrm{e}}=5,344\right.$, and $F_{2}(1,23)=32.95, M S_{\mathrm{e}}=7,848$, both $p$ s $\left.<.001\right]$. The data suggest the existence of symmetrical two-way, rather than 
Table 5

Experiment 4: Mean Response Times (RTs, in Milliseconds), Percentage of Misses (PM), and Standard Error for Familiar Targets Matched in Duration and Recognizability as a Function of Prime-Target Relation and Condition

\begin{tabular}{|c|c|c|c|c|c|c|c|c|c|c|c|c|c|c|}
\hline \multirow[b]{4}{*}{ Prime } & \multicolumn{14}{|c|}{ Target } \\
\hline & \multicolumn{8}{|c|}{ Melody } & \multicolumn{6}{|c|}{ Lyrics } \\
\hline & \multicolumn{4}{|c|}{ Related } & \multicolumn{4}{|c|}{ Unrelated } & \multicolumn{4}{|c|}{ Related } & \multicolumn{2}{|l|}{ Unrelated } \\
\hline & RT & $S E$ & PM & $S E$ & RT & $S E$ & PM & $S E$ & RT & $S E$ & $\mathrm{PM}$ & $S E$ & $S E \mathrm{PM}$ & $S E$ \\
\hline Same-domain & 1,485 & 52 & 24 & 2 & 1,551 & 45 & 27 & 2 & 1,286 & 56 & 24 & 3 & $1,347 \quad 54 \quad 26$ & 2 \\
\hline Cross-domain & 1,647 & 52 & 19 & 3 & 1,724 & 58 & 24 & 3 & 1,425 & 53 & 25 & 2 & $1,475 \quad 52 \quad 30$ & 2 \\
\hline
\end{tabular}

one-way, interactions between melody and text in song memory.

The error pattern follows essentially that of the response times, as can be seen in Table 5. The only effect to reach significance was the prime-target relation. Targets in related prime-target pairs were more accurately recognized than those in unrelated pairs $\left[F_{1}(1,92)=20.95, M S_{\mathrm{e}}=\right.$ 0.0032 , and $\left.F_{2}(1,23)=19.37, M S_{\mathrm{e}}=0.0035, p<.001\right]$.

Altogether, latencies and miss rates provide evidence for the existence of reciprocal connections between melody and text in memory representation for songs. The only influence that a change of domain between primes and targets had on performance was a general slowing effect. Cross-domain conditions yielded longer response times than same-domain conditions with both sung and spoken targets $\left[F_{1}(1,92)=8.43, M S_{\mathrm{e}}=129,080\right.$, and $F_{2}(1,23)=$ $126.21, M S_{\mathrm{e}}=11,071$, both $\left.p \mathrm{~s}<.005\right]$. This slowing was not associated with a significant increase in miss rate $\left(F_{1}\right.$ and $\left.F_{2}<1\right)$. Perhaps this effect reflects the additional demand created by the presence of noise during the normalization process that is likely to occur when one is listening to different modes of expression in rapid succession.

\section{GENERAL DISCUSSION}

In the present research, we have adapted a classical experimental technique - auditory priming - to the study of the relations between text and tune in song memory. This was done by auditorily presenting two short segments taken from the same song, or from different but equally familiar songs, in rapid succession. To promote access to the memory representations of the songs, the format of presentation of text and tune was modified. The melody was sung using the syllable/la/ and the lyrics were spoken. Despite the introduction of drastic changes in the modes of expression and in the order of presentation of prime and target, the recognition of targets was facilitated by a prime coming from the same song in each of the 16 conditions tested in the present study. These results not only demonstrate the effectiveness of the priming technique to reveal memory organization for songs but also provide novel information regarding the way melody and text are related in song memory.

The most interesting manifestation of the organization of melody and text in song memory comes from the observation of backward priming effects. In Experiment 2, 3, and 4 , enhanced recognition of the song beginning, be it spoken or sung, was produced by hearing the notes (or the lyrics) that come normally afterward. This counterintuitiveresult suggests that song memory is not organized in a strict temporal order. Moreover, backward priming effects suggest that words and tunes of songs are connected by tight reciprocal links that allow automatic access from text to melody and vice versa.

More generally, the finding of backward priming diminishes the likelihood that the observed effects are the result of strategic adjustments to the task. Backward priming minimizes the implication of an expectancy-based mechanism (e.g., the one proposed by Posner \& Snyder, 1975, and by Neely, 1977) because expectancy has forward directionality. The likelihood that participants are able to generate the backward associate of the prime is very small. Except in rare songs (e.g., "Happy Birthday") where the first line is usually repeated directly afterward (hence, after the prime "to you") or in canon (such as "Frère Jacques") in which another voice may enter with a repeat of the first voice, the prime never connects in time to the song beginning. Hence, the prime does not predict the target.

Similarly, the finding of backward priming in conditions where the prime has both low predictability for the target and low recognizability makes the intervention of another class of expectation biases unlikely. Indeed, it has been argued that a congruency checking mechanism might be automatically triggered by the presence of any relation that can be detected between prime and target in binary decision tasks (e.g., Seidenberg, Waters, Sanders, \& Langer, 1984). The nature of the relation does not matter; it may apply to semantic (Chumbley \& Balota, 1984) or phonological (Radeau, Morais, \& Dewier, 1989) relations between words. As long as a relation between the two items can be detected, it will bias the cognitive system to respond "yes." The lack of relation in unrelated pairs leads the system to respond "no," thereby interfering with the correct "yes" decision that the target is familiar.

For this congruency-matching mechanism to take place, a prime-target relation must be detected. This may have been difficult or not effective in the present situation for several reasons. First, only $25 \%$ of the trials were related, which decreased the benefits of detecting a relation between prime and targets for responding. Second, targets immediately followed prime presentation, with no ISI, thereby minimizing strategic consideration of the prime. Third, and above all, the primes, particularly when sung, 
were hard to recognize. A classical way to assess recognizability is to use $d^{\prime}$ measures; $d^{\prime}$ values close to zero indicate effective masking. In Experiment 1, $d^{\prime}$ scores for unrelated melody targets were not significantly different from zero, indicating that sung parts that do not correspond to song beginnings are not recognizable. Because these sung continuations served as primes in Experiments 2-4, their relation to the following target was masked, especially in Experiments 3 and 4, where the melodic primes were also time-compressed. Spoken primes were more recognizable, yielding $d^{\prime}$ scores different from zero. However, in Experiment 4, primes were masked to some extent by embedding them in noise. This resulted in a net decrease in feelings of familiarity for the spoken primes and yet did not abolish priming. Thus, at least half of the priming effects in the present study were elicited by primes that can be considered as masked.

The observation of masked priming effects between text and tune components of songs converges on the conclusion that priming likely resulted from automatic spread of activation. In the area of word recognition, masked priming has been used as a tool for studying automatic processes. It has been demonstrated that masked primes, which are not consciously perceived, not only fail to diminish priming effects but also can be more effective than visible primes (Forster, 1998). Moreover, some effects are observed only when the prime is masked (e.g., Kouider \& Dupoux, 2001).

Finding backward priming between text and melody components suggests the presence of reciprocal connections of a higher order than temporal contingencies. The connections between text and tune do not seem to result from learning strict contingent associations. If this were the case, priming should occur only when the relation between prime and target respects the sequential order in which they were learned. Access to song representation in memory clearly is more than the simple reactivation of a perceptual experience.

A plausible mechanism that may account for both the tightness and malleability of the connections between text and tune is rhythmic congruency. The rhythmic similarity between the prosodic accent structure of spoken words and the metric structure of the melody is striking and has long been noted by linguists (e.g., Hayes \& Kaun, 1996; Lerdahl \& Jackendoff, 1983). Moreover, Palmer and Kelly (1992) have shown that linguistic accent structure and musical meter are generally aligned in Western songs. Hence, rhythmic structure, as determined by the number of syllables (notes) and the location of primary stress, may serve as a compatible format to set words to tones. By this account, hearing a particular stress pattern in a melody (or spoken text) may activate a metrical grid that constrains the type of text (melody) that is compatible with it. A rhythmic congruency account of song priming may also explain how nonsequential song parts are related: A common metrical grid is typically used throughout the same song and it generally differs from the metrical grid of another song. Therefore, metric structure provides a means to organize song lines of an entire song in a common hierarchical structure, thereby relating nonadjacent song components. To our knowledge, this metric account of the connections between lyrics and tunes has never been tested in song memory, only in performance (Palmer \& Kelly, 1992).

It is worth noting that even if the memory representations of song components are not strictly sequential, they do preserve order information, especially for song beginnings. Beginnings are much easier to recognize than are other song parts. This is true for both text and melody. As shown in Experiment 1, it is very difficult to recognize a few sung notes when they are presented in isolation or after unrelated lyrics. In contrast, the first few words or notes of a song are reliable triggers for memory. This suggests that beginnings are marked differently in memory. They act as anchor points for the whole song. Front anchoring, a common property of temporal sequences (Anderson, 1983), refers to the fact that the beginning of a sequence is a determinant factor of the speed of recognition and recall of the sequence in question. For instance, the letters $\mathrm{CN}$ are much more likely to call to mind $\mathrm{CNN}$ than are the letters NN. Song recognition appears to be similar in this regard.

Together, these conclusions on the nature of the connections between text and tune in song memory undermine the validity of the hypothesis that drove the present study. We started this study with an associationist conception of song memory according to which the connections between the text and tune components reflect their original coupling. Because lyrics are systematically sung on a single melodic line, they were expected to be more tightly connected to music than vice versa. The melody was conceived as having more autonomy relative to text because the same melody usually carries different lyrics in the same song. We found some support for this idea in Experiments 2 and 3 , where lyrics seemed to prime melody more effectively than vice versa. However, the evidence is weakened by the fact that, in these two experiments, lyrics were much easier to recognize than melody. Hence, a more trivial account for the asymmetrical pattern observed is that lyrics make contact with the memory representation earlier than the corresponding melody. When access to the memory representation was matched in terms of recognizability, by adding noise to the lyrics in Experiment 4, the text and the tune were equally effective in priming each other. Therefore, the results are more compatible with the view that melody and text of songs are related by symmetrical bidirectional connections.

An enduring problem in the present study was the constantly higher recognizability of lyrics over tunes. This lyrics advantage cannot be explained by the fact that the name of a song generally corresponds to its initial lyrics. In Experiment 1, the targets presented for recognition never corresponded to the song beginnings. Yet, a large text advantage was obtained. Lyrics seem easier to recognize in general. This is consistent with the literature. In all the published studies in which memory for the two components has been tested, a large advantage for words over melodies has been noted (Crowder et al., 1990; Feierabend, Saunders, Holahan, \& Getnick, 1998; Hébert \& Peretz, 
2001; Morrongiello \& Roes, 1990; Peretz, Belleville, \& Fontaine, 1997; Samson \& Zatorre, 1991; Seraf ine et al., 1984). This text advantage might reflect the fact that syllables are more diagnostic of words than tones are diagnostic of familiar tunes. It takes six notes, on average, to recognize a highly familiar tune (Dalla Bella, Peretz, \& Aronoff, 2003), whereas it takes only one to two syllables to recognize a frequent word (e.g., Grosjean, 1980).

In conclusion, the present study provides a new tool for exploring memory for songs. One advantage of the technique is that it allows the study of a natural material without the problem of ceiling effects. More importantly, the priming technique allows the on-line measurement of indirect, probably automatic, effects of memory. These two facets of the technique open new avenues for the study of song memory because prior research focused mostly on the explicit memory recognition of novel songs. Above all, the priming technique allows the study of relations at different levels of processing. This flexibility is particularly interesting in the case of songs because the nature of the connections that relate the text to the music is not well captured by simple time contingencies, and is best understood in terms of perceptual rhythmic congruencies.

\section{REFERENCES}

ANDERSON, J. R. (1983). The architecture of cognition. Cambridge: Harvard University Press.

Berthier, J. C. (1979). 1000 chants. Les Presses de l'Ile-de-France.

Besson, M., Fa ta, F., Peretz, I., Bonnel, A.-M., \& Requin, J. (1998). Singing in the brain: Independence of lyrics and tunes. Psychological Science, 9, 494-498.

Chumbley, J. I., \& Balota, D. A. (1984). A word's meaning affects the decision in lexical decision. Memory \& Cognition, 12, 590-606.

Collins, A. M., \& LofTus, E. F. (1975). A spreading-activation theory of semantic processing. Psychological Review, 82, 407-428.

Crowder, R., Serafine, M. L., \& RePP, B. (1990). Physical interaction and association by contiguity in memory for the words and melodies of songs. Memory \& Cognition, 18, 469-476.

Dalla Bella, S., Peretz, I., \& Aronoff, N. (2003). Time course of melody recognition: A gating paradigm study. Perception \& Psychophysics, 65, 1019-1028.

Feierabend, J., Saunders, T., Holahan, J., \& Getnick, P. (1998). Song recognition among preschool-age children: An investigation of words and music. Journal of Research in Music Education, 46, 351359.

FORSTER, K. (1998). The pros and cons of masked priming. Journal of Psycholinguistic Research, 27, 203-233.

GrosJeAn, F. (1980). Spoken word recognition processes and the gating paradigm. Perception \& Psychophysics, 28, 267-283.

HAYES, N., \& KAUN, A. (1996). The role of phonological phrasing in sung and chanted verse. Linguistic Review, 13, 243-303.

HÉBert, S., \& Peretz, I. (2001). Are text and tune of familiar songs separable by brain damage? Brain \& Cognition, 46, 169-175.

Hébert, S., Racette, A., Gagnon, L., \& Peretz, I. (2003). Revisiting the dissociation between singing and speaking in expressive aphasia. Brain, 126, 1838-1850.

Kahan, T. A., Neely, J. H., \& Forsythe, W. J. (1999). Dissociated backward priming effects in lexical decision and pronunciation tasks. Psychonomic Bulletin \& Review, 6, 105-110.

KILGOUR, A. R., JAKOBSON, L. S., \& CUDDY, L. L. (2000). Music train- ing and rate of presentation as mediators of text and song recall. Memory \& Cognition, 28, 700-710.

KORIAT, A. (1981). Semantic facilitation in lexical decision as a function of prime-target association. Memory \& Cognition, 9, 587-598.

KouIDER, S., \& Du POUX, E. (2001). A functional disconnection between spoken and visual word recognition: Evidence from unconscious priming. Cognition, 82, B35-B49.

LERDAHL, F., \& JACKENDOFF, R. (1983). A generative theory of tonal music. Cambridge, MA: MIT Press.

Meyer, D., \& SChVANE Veldt, R. (1971). Facilitation in recognizing pairs of words: Evidence of a dependence between retrieval operations. Journal of Experimental Psychology, 90, 227-234.

Morrongiello, B., \& RoEs, C. (1990). Children's memory for new songs: Integration or independent storage of words and tunes? Journal of Experimental Child Psychology, 50, 25-38.

NEELY, J. (1977). Semantic priming and retrieval from lexical memory: Roles of inhibitionless spreading activation and limited-capacity attention. Journal of Experimental Psychology: General, 106, 226-254.

NeEly, J. H. (1991). Semantic priming effects in visual word recognition: A selective review of current findings and theories. In D. Besner \& G. Humphreys (Eds.), Basic processes in reading: Visual word recognition (pp. 264-336). Hillsdale, NJ: Erlbaum.

PAlmer, C., \& Kelly, M. (1992). Linguistic prosody and musical meter in song. Journal of Memory \& Language, 31, 525-542.

PeretZ, I. (1993). Auditory agnosia: A functional analysis. In S. McAdams \& E. Bigand (Eds.), Thinking in sound: The cognitive psychology of human audition (pp. 199-203). New York: Oxford University Press.

Peretz, I. (1996). Can we lose memories for music? The case of music agnosia in a nonmusician. Journal of Cognitive Neurosciences, $\mathbf{8}, 481$ 496.

Peretz, I., Belleville, S., \& Fontaine, F. S. (1997). Dissociations entre musique et langage après atteinte cérébrale: Un nouveau cas d'amusie sans aphasie. Revue canadienne de psychologie expérimentale, 51, 354367.

PoSNER, M., \& SNYder, C. (1975). Attention and cognitive control. In R. L. Solso (Ed.), Information processing and cognition: The Loyola symposium (pp. 55-85). Hillsdale, NJ: Erlbaum.

Radeau, M., Morais, J., \& Dewier, A. (1989). Phonological priming in spoken word recognition: Task effects. Memory \& Cognition, 17, 525-535.

SAMSON, S., \& ZATORRE, R. (1991). Recognition for text and melody of songs after unilateral temporal lobe lesion: Evidence for dual encoding. Journal of Experimental Psychology: Learning, Memory, \& Cognition, 17, 793-804.

Seidenberg, M., Waters, G., Sanders, M., \& Langer, P. (1984).Preand post-lexical loci of contextual effects on word recognition. Memory \& Cognition, 12, 315-328.

Serafine, M. L., Crowder, R. G., \& Repp, B. (1984). Integration of melody and text in memory for song. Cognition, 16, 285-303.

Serafine, M. L., Davidson, J., Crowder, R. G., \& RepP, B. (1986). On the nature of melody-text integration in memory for songs. Journal of Memory \& Language, 25, 123-135.

Tzelgov, J., \& EBEn-EzRA, S. (1992). Components of the betweenlanguage semantic priming effect. European Journal of Cognitive Psychology, 4, 253-272.

Wathanasin, S., Birkett, T. E., Russell, P. T., \& Altmann, G. T. M. (1991). Experimenter Package for the Apple Macintosh Computer. Young, A., Hellawe ll, D., \& De HaAn, E. (1988). Cross-domain semantic priming in normal subjects and a prosopagnosic patient. Quarterly Journal of Experimental Psychology, 40A, 561-580.

ZWITSERLOOD, P. (1996). Form priming. Language \& Cognitive Processes, 11, 589-596.

(Manuscript received November 30, 2002; revision accepted for publication May 31, 2003.) 